\title{
Changes in the anterior segment as a presenting feature in leukaemia
}

\author{
G. N. BHADRESA \\ Upton-by-Chester
}

Involvement of the anterior segment in leukaemia is thought to be common, although it is often slight and easily overlooked (Allen and Straatsma, ig6r). The following patient came for consultation because of changes in the anterior segment, and although apparently quite healthy she was in the early stages of leukaemia and was soon to succumb from the overt disease.

\section{Case Report}

A married woman aged 8r years was referred by her general practitioner who was treating her for a corneal ulcer on the right eye. Her general health was good apart from a mild gastric upset a few weeks previously.

OGULAR EXAMINATION

Day I

Visual acuity : $6 / 24$ both eyes unaided.

Right eye : A ring ulcer $\mathrm{I} \mathrm{mm}$. from the limbus stained positively with fluorescein. There were small infiltrates at the limbus, above and temporally and below. The anterior chamber was clear, with posterior polar lens opacities.

Left eye : The anterior segment was normal apart from posterior polar lens opacities.

Day 2

Right eye : The numbers of infiltrates increased, some of them being large, extending towards the centre, and also raising the conjunctiva peripherally. Corneal oedema, folds in Descemet's membrane, and a moderate flare in the anterior chamber were observed.

ADMISSION TO HOSPITAL

She was admitted for investigation and intensive treatment. A hyphaema developed in the right eye and the eyelids became oedematous on both sides.

She had irregular pyrexia and tended to be restless. She was obese and anaemic-looking, with a few petechiae on the arms and chest. No other abnormality was noted.

\section{LABORATORY INVESTIGATIONS}

Haemoglobin $62 \mathrm{mg}$. per cent.; white cell count $\mathrm{I} 16,000 / \mathrm{mm} \cdot{ }^{3}$ (33 per cent. myeloblasts). Sternal marrow 8 I per cent. myeloblasts. 
Day 3

There was a subconjunctival haemorrhage in the right eye, which was treated with prednisolore $50 \mathrm{mg}$./day and Myeleran $4 \mathrm{mg}$./day.

Day 4

Infiltrates were also seen at the limbus in the left eye.

TERMINATION

Her general condition was improving, when on the $15^{\text {th }}$ day she suddenly went into cardiac failure and died.

Post mortem examination (Figs i to 3 )

The liver, spleen, kidneys, and heart were normal in size and weight. Sections of pericardium, myocardium, liver, spleen, lungs, and kidneys showed capillaries filled with myeloblasts. Sections of both eyes showed heavy cellular infiltrates at the limbus and adjoining superficial corneal stroma with scarring and indentation. The anterior chamber contained serous exudates and clumps of large basophilic cells with indented nuclei deposited on the posterior corneal surface. The trabeculae and canal of Schlmem, iris, and ciliary body were infiltrated, and the retinal vessels, and those at the disc and optic nerve, were choked with similar cells. Leukaemic infiltration was also present in the scleral channels, attached muscles, Tenon's capsule, and the episcleral tissues.

\section{Discussion}

Foster Moore (1925), in an analysis of 138 cases of leukaemia of all types, observed that while 87 per cent. showed retinal changes, external changes were infrequent; these in cluded slight ptosis, subconjunctival haemorrhages, ecchymosis of the lids, and proptosis.

Allen and Straatsma ( 1961 ), in a pathological examination of 76 eyes, observed that almost half showed ocular involvement, which was more common in acute cases. Scleral and limbal abnormalities were common, but were slight and easily overlooked. The most frequent sign was slight thickening of the epibulbar tissues near the limbus, occasionally progressing to gelatinous yellow or flesh-coloured nodules. In no case was the central cornea involved. Corneal ulceration was not mentioned in any of these cases.

In a case of acute myeloblastic leukaemia reported by Jamotton, Massa, de Vloo, and Fievet $(1963)$ in a patient aged $34 \mathrm{yrs}$, the anterior segment appeared to be normal, although there was infiltration into the choroid, retina, and optic nerve with papilloedema.

Of four fatal cases of leukaemia observed by Hocking and McTaggart (1963), one had a cataract extraction, but died after the operation of acute myeloblastic leukaemia; this patient does not appear to have had changes in the anterior segment.

\section{Summary}

The case is described of a patient who presented with a corneal ulcer and infiltrates, who shortly died of acute myeloblastic leukaemia.

I wish to thank Mr. W. D. Hopkins, consultant ophthalmologist, for permission to publish this case. The preparation of the histological sections and the pathological report by Prof. Norman Ashton of the Institute of Ophthalmology, are gratefully acknowledged. 
(I)

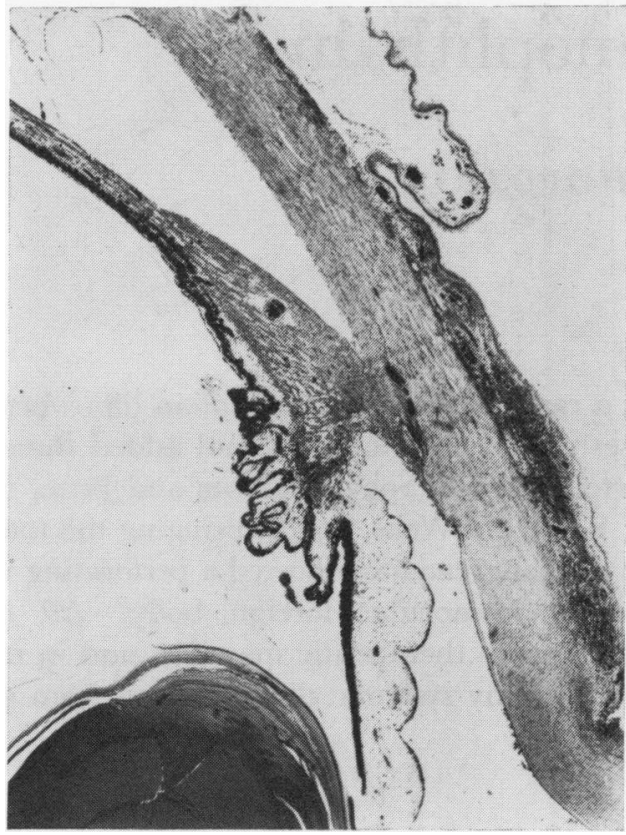

(3)

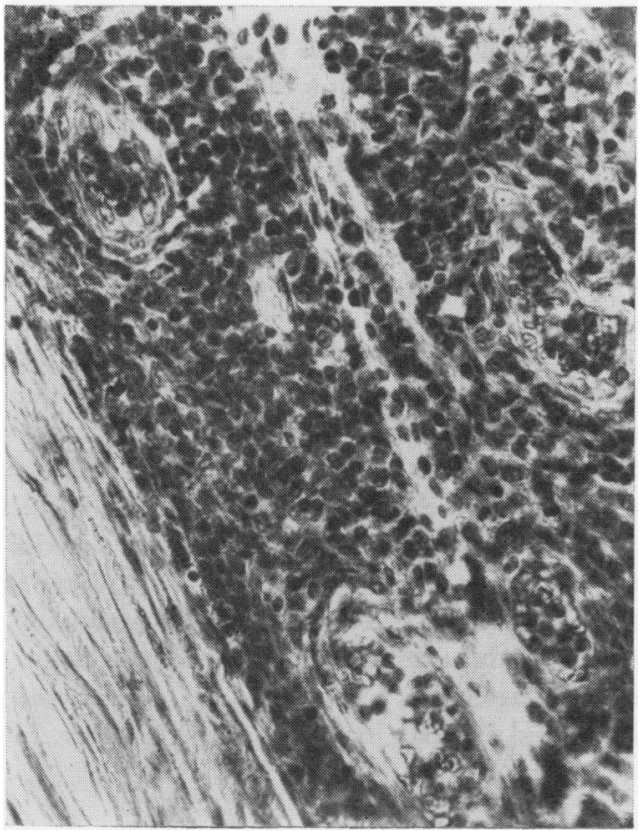

(2)

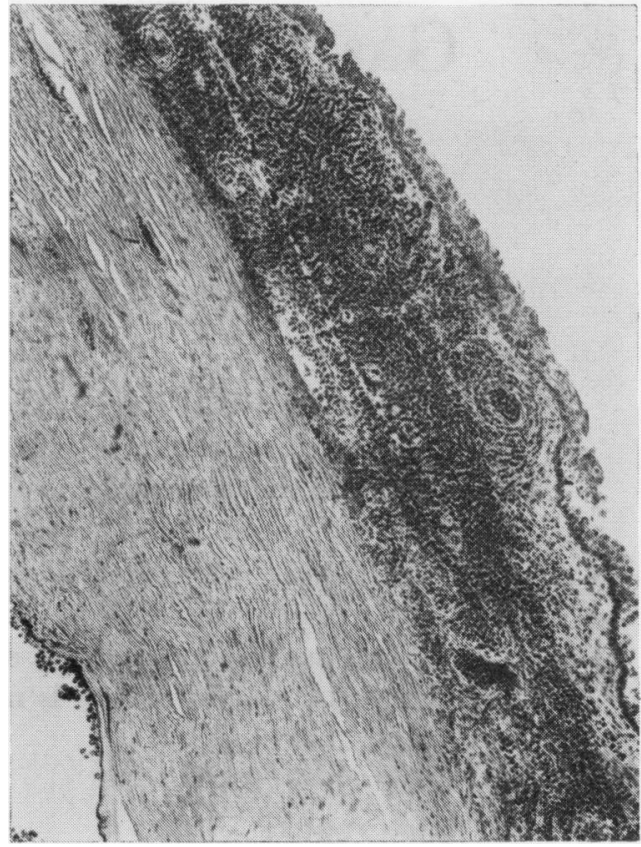

hist

FI G. I Heavy cellular infiltration at the limbus; superficial corneal ulcer; deposition of cells on the posterior corneal surface $\times 17$

FIG. 2 Heavy subconjunctival infiltration at the limbus $\times 60$

FIG. 3 Intravascular and perivascular infiltration by myeloblasts $\times .250$

\section{References}

Allen, R. A. and StraAtsma, B. R. (196I) Arch. Ophthal. (Chicago), 66, 490 hocking, D. R. and mctaggart, D. R. (1963) Med. J. Aust., 2, 957 JAMOtTon, L. MASSA, J. M. DE Vloo, N., and fievet, J. P. (1963) Bull. Soc. belge Ophtal., 135, $5^{15}$ MOORE, R. FOSTER (1925) "Medical Ophthalmology". 2nd ed. pp. 10, 104. Churchill, London 